\title{
Rio Branco Sport Club e Paranaguá/PR: Representações Políticas
}

\author{
Natali Calderari ${ }^{1}$ \\ Mayra Taiza Sulzbach ${ }^{2}$
}

\begin{abstract}
Resumo: A pesquisa "Futebol além das quatro linhas: Identidade e Pertencimento no Rio Branco Sport Club - Paranaguá/PR" buscou símbolos de pertencimento dos torcedores ao Município, considerando a cultura como a base para a promoção de identidades e, estas, as que resultam em pertencimento com a sua afirmação e representação. Através da leitura histórica, da análise de discursos de manifestações da internet e de entrevistas foram identificadas as ligações políticas. A representação política do Município está relacionada aos dirigentes do Rio Branco, sendo este um fator histórico do Clube. A relação entre a política e o Clube é apresentada na forma de elogio aos políticos pelo que fizeram ao Rio Branco ou de crítica, pela falta de apoio da prefeitura, expressando dependência. Por vezes, as representações de ambos se confundem, onde as ações que cabem ao Clube são atribuídas aos políticos. Além disso, a Torcida Organizada manifestou apoio à candidatos a prefeito e vereador. As ações da Torcida Organizada e do Clube com o Município estabelecem relações de poder social dentro e fora do campo a partir dos papéis que assumem nas representações. A diretoria e os políticos representam o poder no Clube e no Município, respectivamente, mantendo as estruturas suas manutenções no poder. A torcida na relação estabelecida com um e outro assume o trabalho de base para manutenção dos poderes, criticando-os sobre o que não fazem, fazendo.
\end{abstract}

Palavras-chave: Futebol. Paranaguá. Política.

\section{Rio Branco Sport Club and Paranaguá / PR: Political Representations}

\begin{abstract}
The search "Football beyond the four lines: Identity and Belonging in Rio Branco Sport Club - Paranaguá / PR" sought symbols of the fans' adherence to the Municipality, considering the culture as the basis for the promotion of identities and, these, those that Result in belonging with their affirmation and representation. Through historical reading, the analysis of Internet manifestations and interviews, political connections were identified. The political representation of the Municipality is related to the leaders of Rio Branco, being this a historical factor of the Club. The relationship between politics and the Club is presented in the form of praise to politicians for what they did to Rio Branco or for criticism, for the lack of support from the city hall, expressing dependency. Sometimes the representations of both are confused, where the actions that fit the Club are attributed to the politicians. In addition, the Organized Twist expressed support for candidates for mayor and councilor. The actions of the Organized Fan and the Club with the Municipality establish relations of social power inside and outside the field based on the roles they assume in the representations. The board and politicians represent the power in the Club and in the Municipality respectively, keeping the structures their maintenance in power. The cheer in the relationship established with one and the other assumes the basic work for maintaining the powers, criticizing them about what they do not do, doing.
\end{abstract}

Keywords: Football. Paranaguá. Policy.

- Enviado em 01/05/2017

- Aprovado em 17/05/2017

\footnotetext{
${ }^{1}$ Mestranda em Desenvolvimento Territorial Sustentável (UFPR), bolsista CAPES/Fundação Araucária. Uma versão preliminar desse texto foi apresentada no VIII Seminário Nacional de Sociologia e Política realizado de 17 a 19 de maio de 2017 na UFPR. E-mail:natali_Calderari@hotmail.com.

2 Pós-doutora em Sociologia Econômica, Professora do Programa de Pós-Graduação em Desenvolvimento Territorial Sustentável UFPR. Uma versão preliminar desse texto foi apresentada no VIII Seminário Nacional de Sociologia e Política realizado de 17 a 19 de maio de 2017 na UFPR. E-mail: mayrasulzbach@yahoo.com.br
} 


\section{INTRODUÇÃO}

A pesquisa "Futebol além das quatro linhas: Identidade e Pertencimento no Rio Branco Sport Club - Paranaguá/PR" buscou símbolos de pertencimento dos torcedores ao Município, considerando a cultura como a base para a promoção de identidades e, estas, as que resultam em pertencimento com a sua afirmação e representação. Durante o percurso observou-se uma forte relação entre os torcedores, jogadores e dirigentes do Clube e os políticos do Município, que será apresentada neste trabalho. As primeiras relações foram constatadas na história do Município e do Clube. Na sequência, elas também foram observadas no discurso dos torcedores e pessoas ligadas ao Clube.

O Rio Branco não atua no Município apenas nos jogos do time de futebol profissional nos campeonatos paranaenses, ele promove ações sociais o ano inteiro. Estas, voltadas para a população de Paranaguá, são promovidas tanto pelo Clube quanto pelos membros da Torcida Organizada, tendo sua imagem associada ao Rio Branco Sport Club e apropriadas pelos torcedores e população de maneira a promover dirigentes e jogadores no cenário político do local.

Através de pesquisa bibliográfica (histórica), da análise de discurso de manifestações da internet e de entrevistas relacionadas ao Clube foram identificadas ligações políticas. $\mathrm{O}$ ambiente virtual é hoje um dos principais meios de comunicação e interação de comunidades de pessoas que possuem interesses em comum, o que levou a pesquisa a seleciona-lo como meio de captura de informações para análise. Foram levantadas publicações e comentários de publicações de 2016: na página oficial do Rio Branco no Facebook; na página do grupo de torcedores do Rio Branco no Facebook intitulado "Rio Branco Sport Club - PR"; na página oficial da Torcida Camisa Vermelha e Branca no Facebook; no site do Globo Esporte; e no site do Rio Branco. Publicações e; em comentários de outras páginas compartilhadas. As entrevistas foram realizadas com dirigente, ex-jogadores, membros da torcida e analistas do esporte.

Para defesa dos argumentos, este trabalho está dividido em cinco partes, além desta e das considerações finais. A primeira apresenta ligações sociais, econômicas e políticas entre a história 
do Clube e do Município. Na sequência são apresentados e discutidos como as ações sociais, o estádio e os torcedores estabelecem uma relação entre o Rio Branco e a política de Paranaguá.

\section{LIGAÇÕES HISTÓRICAS}

A história do futebol do Rio Branco Sport Club, desde sua fundação no início dos anos 1900, se entrelaça com a história de Paranaguá, refletindo a inserção do Clube no Município. As relações econômicas e políticas se mostraram presentes em diferentes momentos da história de ambos.

O RBSC teve seus primeiros anos de vida com o início do Ciclo da Madeira (1920/1955) em Paranaguá, recebendo doação de madeiras para a construção das arquibancadas do primeiro campo, na Praça João Gualberto. Ainda no âmbito da influência das atividades do Porto, no Ciclo do Café, um dos mais duradouros (da década de 1950 a década de 1980) e importantes para o Porto D. Pedro II e para o Rio Branco, as intensas exportações de café levaram a Paranaguá grandes empresas que fizeram doações de sacas de café ao Clube para venda. Para Machado (2003, p. 97), "enquanto o café esteve em alta, o Rio Branco sobreviveu. Quando o café sofreu um debacle, o Leão sucumbiu".

A Estrada de Ferro que propiciou a ligação entre Paranaguá (litoral) com o planalto, favorecendo a economia do lugar, permitiu que as delegações de times paranaenses deslocaremse a Paranaguá, assim como dos jogadores do Leão participarem de jogos em outros municípios, influenciando até nos horários de realização dos confrontos.

Algumas construções presentes no município, em algum momento, têm sua trajetória histórica cruzada com a do Rio Branco. A Escola Normal Primária de Paranaguá, atual Instituto de Educação Dr. Caetano Munhoz da Rocha, que foi construída ao lado das arquibancadas do campo onde o RBSC treinava e jogava, influenciando na mudança do campo para a "Estradinha". A Escola é hoje um dos principais edifícios históricos tombados como patrimônio do estado do Paraná e um dos principais estabelecimentos de educação do local. O Club Litterario, presente na vida dos parnanguaras desde sua criação, em 1872, foi local de eventos festivos do Rio Branco SC, 
mantendo, em parceria com o Clube, o tradicional baile carnavalesco "Vermelho e Branco", fazendo referência às cores do Leão.

A representação pública do Clube e de Paranaguá, segundo Machado (2003, p. 96), é marcada por "muitos presidentes e diretores do Rio Branco SC - ao longo da história - sempre estiveram ligados ao esquema político econômico". Na década de 1990 o vereador Mário Roque foi eleito Presidente do Leão, e posteriormente teve o apoio da torcida para ser eleito Prefeito de Paranaguá.

A representação política do Município está relacionada aos dirigentes do Rio Branco, sendo este um fator histórico do Clube.

\section{AÇÕES SOCIAIS: TORCIDA ORGANIZADA E CLUBE}

A Torcida Organizada ao promover ações sociais acaba por representar o Clube no Município, aproximando a população ao Rio Branco. Para um dos diretores da TUCVB em decorrência do Clube fazer pouco por Paranaguá, a Torcida Organizada assume a responsabilidade em levar o Rio Branco a Paranaguá e angariar torcedores. Neste sentido, as ações sociais auxiliam no processo. Em 2016, a TUCVB promoveu a campanha de doação de sangue, mas pretendia realizar outras. 
FIGURA 1 - CAMPANHA SOCIAL DE AÇÃO DE DOAÇÃO DE SANGUE DA TUCVB

T.U. Camisa Vermelha e Branca

19 de dezembro de 2016 -

Na semana de Natal, a Torcida Uniformizada Camisa Vermelha e Branca, lança campanha para doação de sangue, que ocorrerá no dia 07/01/2017. Venha também fazer parte deste gesto de solidariedade para quem tanto precisa.

Mais informações, via Inbox ou Whatsapp: 41-984933292

Amizade - Lealdade - Tradição... Ver mais

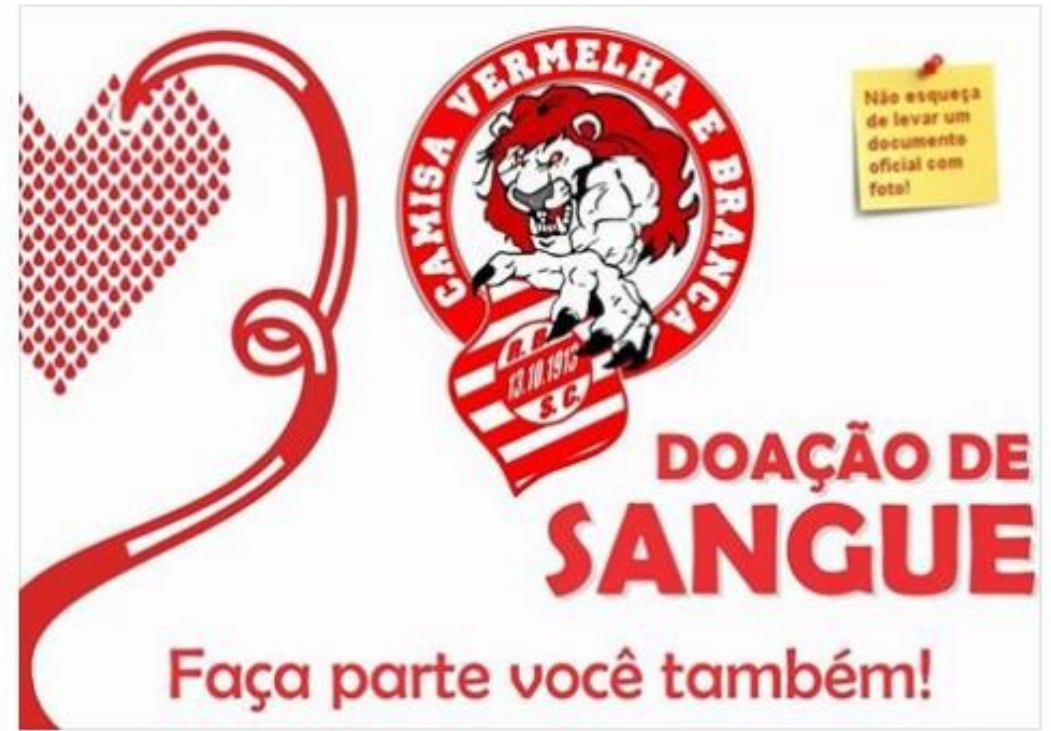

FONTE: Adaptado de T. U. CAMISA VERMELHA E BRANCA

(Disponível em: www.facebook.com/tucvb, 2017)

Ah, a gente sempre faz, na verdade nós lançamos agora uma campanha de doação de sangue, né. Nós, quando teve a última enchente aqui no litoral nós arrecadamos alimentos, né. Esse ano nós pretendemos fazer quatro ações, que é dia das crianças, na páscoa e no natal, pra entregar brinquedo e doce pra criançada. Então essas são as ações que a gente pretende fazer e já fez algumas também no passado (Diretor da TUCVB, em entrevista em 14 de janeiro de 2017).

Acho que o RB faz muito pouco pela cidade. Não existe nada que o Rio Branco faça hoje pela cidade a não ser o futebol (Diretor da TUCVB, em entrevista em 14 de janeiro de 2017).

A torcida tem uma relação muito forte com a cidade pelas ações sociais que faz. $O$ clube eu acho que pode ainda fazer ainda algumas coisas mais pra ajudar, isso e aquilo. Como escolinha de futebol carente, isso e aquilo, que o Rio Branco ainda não tem. Dizem que tem uma secundária mas a gente não sabe que não é do Rio Branco, então... pra nós não é uma ação diretamente do Rio Branco (Diretor da TUCVB, em entrevista em 14 de janeiro de 2017). 
Segundo um dos dirigentes e um funcionário do Clube, a atuação do Rio Branco vai além do Campeonato Paranaense. O "Leões do Futuro" é um projeto social do Clube que atende mais de 300 crianças em Paranaguá. O Clube também realiza projetos sociais com parcerias, tais como a Associação de Pais e Amigos dos Excepcionais - APAE, que promove a interação dos jogadores com alunos e com a administração municipal, realizando campanhas ao enfrentamento de problemas, como o da epidemia de dengue no ano de 2016.

[...] Projeto social Leões do Futuro, que atende mais de 300 crianças. E aí algumas ações que a gente faz durante o ano, corriqueiramente, pra tentar aproximar o torcedor e até mesmo estar contribuindo para a cidade (Dirigente, em entrevista em 23 de dezembro de 2016).

É, aqui, terça e quinta, nós temos o Leões do Futuro, que não sei se você conhece, que é aqui na Olé. Nós temos professores na llha dos Valadares, e o RB já teve de 12 a 13 escolinhas espalhadas pelo bairro, e tá voltando agora com calma, escolhendo os professores, que é um trabalho sério de a gente fazer (ex-jogador e funcionário 2, em entrevista em 23 de dezembro de 2016).

Tinha um saquinho de leite, eu não sei se você se lembra, que o falecido Roque fez uma vaca mecânica e fez um saquinho de leite, aquilo foi a coisa mais linda pra Paranaguá, porque a minha molecada eles não tinham o alimento, eles não tinham o que comer, e o presidente da associação do bairro ele tinha um comércio, e ele tentou me ajudar, "pô ....... eu vou pegar pra você esses saquinhos de leite" e trazia lá 150, 200 saquinhos de leite, e tinha menino que não ia embora por causa daquele saquinho de leite, vaca mecânica, leite de soja sabe. Eles fizeram aqueles saquinhos de leite e o Roque distribuía aqui nas escolas e eu conseguia, e tinha um menino que esperava as $11 \mathrm{~h} 30$, terminou no colégio pra tomar 3, 4 saquinhos daquele e saía todo feliz. Então o RB tem uma história bacana com a categoria de base, tem um negócio bem interessante, é o futuro do clube (ex-jogador e funcionário 2, em entrevista em 23 de dezembro de 2016).

Sempre que tem qualquer coisa assim que seja, que precise de um apelo maior a gente acaba encampando e acaba também contribuindo porque o futebol é a paixão e o torcedor vem, o torcedor vai ver, e a gente sabe que acaba contribuindo de uma forma efetiva (Dirigente, em entrevista em 23 de dezembro de 2016).

Utilizar essa mobilização para chamar a atenção pra determinadas situações. Nós temos também a parceria com a APAE, que é uma parceria muito legal que a gente tem. Todos os anos os jogadores vão lá, vão visitar, a gente faz algumas contribuições, os alunos da APAE entram, em pelo menos um jogo do clube, junto com os atletas (Dirigente, em entrevista em 23 de dezembro de 2016).

Independente das ações ocorrerem por meios digitais ou em espaços físicos do Município, estas são incorporadas no cotidiano da população do local. 


\section{O ESTÁDIO}

Colaborando com as ações, o estádio, onde ocorrem às competições, é um espaço físico, que reúne populações diversas (homens e mulheres; crianças, jovens, adultos e idosos; diferentes classes de renda) e em grande número, atuando como um espaço de representação no Município que é adotado como um local de apropriação à representação política.

No estádio, a torcida apoia os jogadores, motivando-os às vitórias. O estádio é o cenário do espetáculo de um jogo de futebol e, no caso da Estradinha, acredita-se que influencie nos resultados das partidas.

Mas na época, na era do Rio Branco, principalmente nos anos de 50,60, 70 e 80, a torcida enchia a estradinha e era alí um alçapão. Os times que vinham joga aqui, Coritiba, Atlético, Ferroviário, Londrina, Maringá, Operário, Guarani de Ponta Grossa, era difícil ganhar do Rio Branco (Radialista, em entrevista em 23 de dezembro de 2016).

Nos estádios de futebol, os jogos são recorrentes e reúnem um grande número de homens, os quais ainda exercem poder na estrutura da família. Condições que apoiam formação de representações, entre elas as políticas.

\section{OS TOCEDORES}

O torcedor busca, através do Clube que o representa, emoções, pois nem sempre as vitórias ocorrem. Torcer é uma forma com que o torcedor motiva seu time à vitória, sentindo-se parte da conquista. Com os torcedores parnanguaras a situação não é diferente. 
O público é importante, é muito importante por causa disso. Ele traz emoção, ele traz vontade pro jogador. É isso aí que é importante a torcida (Radialista, em entrevista em 23 de dezembro de 2016).

É as vitória. Quando ele ganha, então nós que somo torcedor, nós ficamo feliz, né. Porque se você torce pra um time quando ele é campeão, você vai ter aquela emoção, muita alegria, né, porque o time foi campeão. É o que o RB traz pra nós né, quando ele tá jogando, se perde ou ganha, mas como a gente é torcedor do Rio Branco do coração, sempre tá alí junto, né. Seja naqueles momento bom ou mau, mas nós tem que tá presente pra ajudar (Torcedor antigo, em entrevista em 21 de janeiro de 2017).

Os jogadores cansam de dizer que com torcida eles conseguem, eles dão aquele gás a mais, isso e aquilo (Diretor da TUCVB, em entrevista em 14 de janeiro de 2017).

A febre do futebol na torcida parnanguara era algo muito grande, sabe. Pena que hoje nós não tenhamos mais isso (Historiador e Escritor, em entrevista em 16 de janeiro de 2017).

\section{O CLUBE}

O Clube e a torcida são resultados de uma construção coletiva, na medida em que os torcedores se vêm como parte integrante do Clube, algumas vezes, como protagonistas da história, como relatam Radialista, Historiador e Escritor e Torcedor em relação aos torcedores do Rio Branco.

Olha, não sou eu que digo... eu que viajei por esse Paraná inteiro, viajei por todos os lugares, a torcida do RB foi apontada como uma das mais vibrantes. Uma das mais vibrantes... hoje não, hoje a torcida tá desgostosa, o time não tem participações boas no campeonato, nesses últimos anos tem disputado pra não descer pra segunda divisão até a última rodada, a torcida tá meio chateada (Radialista, em entrevista em 23 de dezembro de 2016).

A torcida é que carregou o clube nas costas. Essa é a realidade né. Como eu disse, o estádio vivia lotado. O torcedor... não tô me referindo à torcida organizada, tô me referindo à torcida, torcedor, e esse é a razão de ser do clube, não é a torcida organizada. Mas eles também se organizaram né, quando começa essa onda de torcida organizada você tem lá a torcida do leão. Mas enfim, o torcedor parnanguara ele sempre fez questão de comparecer porque, porque ele tava sendo representado pelo time. Esse é o estigma que nós falamos agora da paixão do torcedor, né. Você vai a campo porque aqueles que estão lá correndo atrás da bola, eles estão te representando. É assim que o torcedor 
pensa né. É assim que o torcedor age. E o torcedor de Paranaguá não foi diferente. Ele se engajou nas cores do Rio Branco né, que o Rio Branco é o seu legítimo representante né. Então essa é a importância dele (Historiador e Escritor, em entrevista em 16 de janeiro de 2017).

Então a torcida do RB é uma torcida maravilhosa, porque quando tem jogos vem de todos os clube do interior, do norte do Paraná, Londrina, onde for... sempre aqui o RB tira o primeiro lugar na renda né. Esses time da capital e sempre tá em terceiro lugar porque a torcida vai em peso (Torcedor antigo, em entrevista em 21 de janeiro de 2017).

Que o RB ele é um time antigo né, ele tá com o que... 103 anos. Então um time muito querido né. $\mathrm{O}$ Leão da Estradinha quando tem jogo aqui, a torcida vai em peso (Torcedor antigo, em entrevista em 21 de janeiro de 2017).

\section{A POLÍTICA E O RIO BRANCO}

O pertencimento de torcedores ao Rio Branco é resulta do papel incorporado dos torcedores no espetáculo de representação do jogo, assim, os torcedores promovem sua existência e a existência do próprio clube, pois não há torcedores sem Clube. Nesta mesma lógica, emergem representantes políticos da torcida, como emerge da população, torcedores.

A relação entre a política e o Clube em Paranaguá é observada em comentários de torcedores nas redes sociais relacionadas ao Rio Branco, bem como em entrevistas. A relação entre os representantes políticos do local e o RBSC é realizada ora na forma de elogio aos políticos pelo que fizeram ao Rio Branco, ora na forma de crítica pela falta de apoio da prefeitura. Ambas as formas expressam a dependência do Clube ao poder político, mas se confundem no que cabe ao Clube ou que são dos políticos. 
FIGURA 2 - COMENTÁRIOS RELACIONADOS A POLÍTICA NO MUNICÍPIO NA PÁGINA DO RIO BRANCO

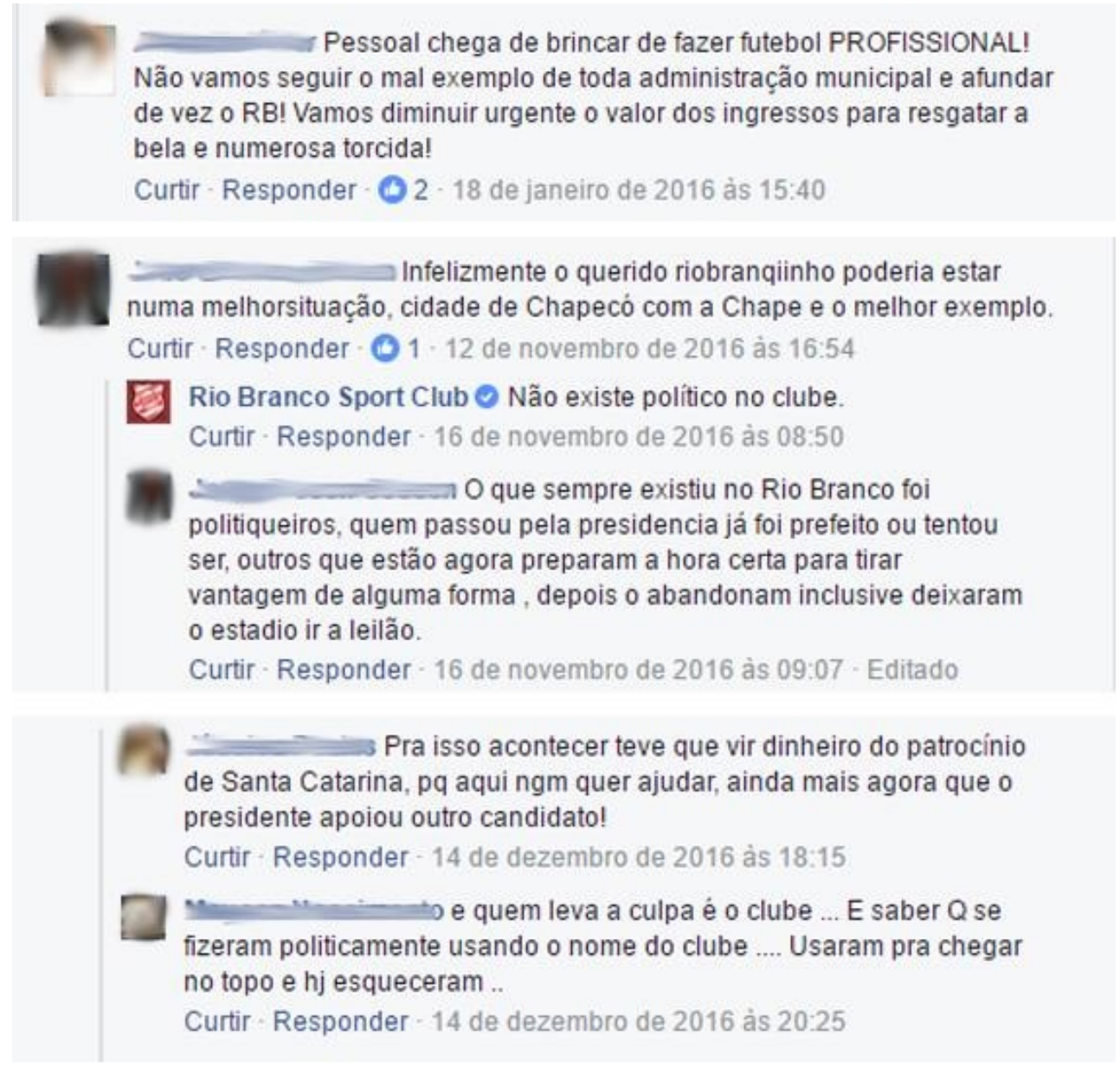

FONTE: Adaptado de RIO BRANCO SPORT CLUB (Disponível em: www.facebook.com/riobrancooficial, 2017)

O que nós precisamo aqui é de um prefeito que ajude o Rio Branco. Porque o Rio Branco tá numa fase... [...] Então agora o Marcelo, que é o prefeito da nossa cidade, e o Maranhão, eles vão arrumar tudo bonitinho. Tá ficando bonito né (o Estádio da Estradinha). Você passou lá e viu como é que tá né (Torcedor antigo, em entrevista em 21 de janeiro de 2017).

Porque o prefeito que ganhou agora, o filho do Roque e o Maranhão, eles tão ajudando muito o Rio Branco. Foi um dos prefeito que, na época em que ele foi prefeito, ele sempre fazia tudo pelo Rio Branco, e Deus levou ele, o Roque, né. Agora ficou o vice, que Deus levou embora, chegou o dia e a hora, e o vice, ele... como vice devia tar sempre alí, no Gigante do Itiberê ou na estradinha, tem jogos que ele não aparece, né. Então pra mim o melhor prefeito de Paranaguá foi o Roque, né. Então agora como o filho dele ganhou, o Marcelo, o Maranhão vice, então agora vai ajudar muito o Rio Branco. Com certeza o RB esse ano ele vai brilhar (Torcedor antigo, em entrevista em 21 de janeiro de 2017).

Outra forma observada da relação entre a política e o Clube foi no apoio da Torcida Organizada a candidatura de prefeito e vereadores nas eleições de 2016. Segundo uma publicação 
na sua página, a TUCVB justifica sua escolha de representação política como uma melhor opção para o Clube.

FIGURA 3 - APOIO DA TUCVB AO CANDIDATO A PREFEITO

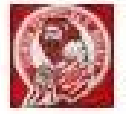

\title{
T.U. Camisa Vermelha e Branca adicionou 4 novas fotos.
}

\begin{abstract}
A Diretoria da Torcida Uniformizada Camisa Vermelha e Branca esteve reunida na tarde de hoje com Marcelo Roque e Arnaldo Maranhão para declarar apoio a candidatura. Nós antes de declararmos apoio ao Marcelo, consultamos os sócios qual seria a melhor opção para o Rio Branco Sport Club, e a escolha foi unânime ao nome do Marcelo, por entender que Marcelo vem de uma família Rio Branquista, e com certeza com a vitória do Marcelo o Rio Branco só ganhará. Pois o sangue Rio Branquista vem de berço. A Torcida pede a nação Rio Branquista que se unam nessa corrente para que o Rio Branco tenha um futuro muito melhor dos dias atuais. Com Marcelo Roque Prefeito (43), o Rio Branco vai voltar a ser Leão. Então mais uma vez a Torcida Camisa Vermelha e Branca pede a força Rio Branquista para quem é de fato Rio Branquista. Agradecemos aos membros e sócios da Camisa Vermelha pelo apoio dado a diretoria da torcida.
\end{abstract}

FONTE: Adaptado de T. U. CAMISA VERMELHA E BRANCA (Disponível em: www.facebook.com/tucvb, 2017)

O atual Prefeito de Paranaguá Marcelo Roque, apoiado pela Torcida, é filho de um expresidente do Rio Branco e ex-prefeito de Paranaguá, Mário Roque, já falecido. O vereador Ratinho, também fazia parte do cenário esportivo, ele era ex-jogador do RBSC, um dos "ídolos" cujo nome era gritado pelos torcedores durante os jogos do Campeonato Paranaense de 2016 (CALDERARI, 2017).

Os políticos, apesar de também fazerem parte da torcida, se elegeram a partir da posição de jogador ou dirigente, ou seja, de destaque entre os membros do Clube. Os políticos e a diretoria representam o poder no Município e no Clube, respectivamente, mantendo nas estruturas suas manutenções nos poderes. Os políticos utilizam a diretoria do Clube para angariar votos de torcedores e a escolha da representação política pelos torcedores decorre do pertencimento destes na estrutura social - Clube. O uso de cargos de diretoria do Clube para acessar os de representação política em Paranaguá não é um fato despercebido, como relata o Historiador e Escritor entrevistado: 
Tem muito presidente lá que se locupletou. Ele tornou-se presidente do Rio Branco porque ele queria ser vereador, prefeito, deputado né (Historiador e Escritor, em entrevista em 16 de janeiro de 2017).

\section{CONSIDERAÇÕES FINAIS}

As ações do Clube e da Torcida Organizada para com o Município estabelecem vínculos sociais dentro e fora do campo a partir dos papéis que esses assumem nas representações. As ações, independente de quem as promovem, Clube ou Torcida Organizada, remetem a imagem do Clube, na medida em que se utilizam dos símbolos deste: cores, emblema, uniforme, entre outros, promovendo-o e consigo seus dirigentes, pois não há instituição sem pessoas.

O Estádio, que faz parte do Município em sua concretude como maior espaço para a reunião de milhares de pessoas sentadas, incorporado pelo futebol congrega diferentes grupos da população que estabelece a ascensão de diferentes representações: torcidas, jogadores, dirigente e políticos.

Os torcedores são, além do espectador, animador, sofredor, entre outros, a população local, são os eleitores do Município. A imagem do Clube diante de suas ações sociais e da Torcida Organizada promove-os para além dos seus espaços de suas representações

A Torcida Organizada na relação estabelecida com o Clube assume o trabalho de base para manutenção dos poderes, criticando-os sobre o que não fazem, fazendo, assim não só captam novos torcedores, mas mantém este grupo em constante manutenção.

Historicamente, o poder econômico no Município se fazia presente na administração do Rio Branco, ocupando cargos de dirigentes e através do Clube sua promoção no cenário político do local. Além do setor privado, a administração pública auxiliou para sua existência e permanência no local: Doação de terrenos; construção de estádio.

A trajetória de vida do Clube e de suas relações com o poder econômico e da administração pública do Município acabaram por criar uma dependência entre estes. Diante 
disso, eleger um político que represente o Clube seria uma solução às constantes demandas do Rio Branco e sua torcida, bem como manter vivo o futebol no local.

\section{REFERÊNCIAS}

CALDERARI, Natali. Futebol além das quatro linhas: Identidade e pertencimento no Rio Branco Sport Club - Paranaguá/PR. 125p. Dissertação (Mestrado em Desenvolvimento Territorial Sustentável) - Programa de Pós-Graduação em Desenvolvimento Territorial Sustentável Universidade Federal do Paraná.

MACHADO, Heriberto Ivan. Rio Branco Sport Club: 90 anos de história. Curitiba: H.I.Machado, 2003. 253 p.

RIO BRANCO Sport Club. Página no Facebook. Disponível em < facebook.com/riobrancooficial> Acesso em 2 de fevereiro de 2017.

T.U. Camisa Vermelha e Branca. Página no Facebook. Disponível em < Disponível em: www.facebook.com/tucvb, 2016> Acesso em 2 de fevereiro de 2017. 